\title{
Possibilities and Limitations of Selected Indexes of Public Orders Effectiveness in Action of International Military Organization NATO Joint CBRN Defence COE
}

\author{
Břetislav Štěpánek \\ Joint CBRN Defence COE, Vyškov, Czech Republic \\ Pavel Otřísal \\ NBC Defence Institute of University of Defence, Vyškov, Czech Republic
}

\begin{abstract}
Mathematical-statistic methods provide proved instruments, suitable for analyzing problems by means of relevant information acquisition to determinate possible consequences of variant decisions. However, it is impossible to affirm that application of these methods in decision activities makes possible to find always solving of all problems with them we meet in environment of NATO. But these methods can provide some important information. Gained information have to be correctly interpreted, appreciated their reliability and determined possibility of their maximal utilization. However, this way gained information represents only one part of decision activities. Every manager problem is to be examined in terms of quantity and quality. Quantitative criteria use direct appreciation and comparison of variants on the basis of predefined values. We use them at the time, if we can required measured quantities determine reliably. If some qualitative criteria should be used, these are to be transformed on measurable values. For example, a qualitative feature- "reliability" can be expressed in intervallic scale. Next step is sorting and variant selection, where we use various methods and techniques. Needed information must be acquired at the same time and considered in light of certain problem. The aim is on the basis of these two informative sources to accept optimal solving variant.
\end{abstract}

Keywords: alliance, analyze, method, index, project, budget

\section{Introduction}

In connection with restructuring the Command Structures of NATO in years 2003-2004, there has been decided to create so-called "Centres of Excellence", whose task is to improve the quality of education and training, increasing levels of interoperability and abilities, doctrine development and experimental consideration and evaluation of new conceptions, always in given specific area according to delegated military-political ordering.

Centres of Excellence are national or multinational sponsored facilities, which provide special abilities and experiences in benefit of whole coalition, above all for supporting its transformation. They make possible to

Břetislav Štěpánek, Dipl. Eng., Ph.D., Joint CBRN Defence COE.

Pavel Otřísal, Dipl. Eng., Ph.D., MBA, NBC Defence Institute University of Defence.

Correspondence concerning this article should be addressed to Břetislav Štěpánek, Dipl. Eng., Víta Nejedlého, Vyškov, 682 01, Czech Republic. E-mail: stepanekb@jcbrncoe.cz. 
improve education and training on qualitative higher level, to improve interoperability and abilities in given area and to participate in the development of doctrines (above all STANAGs, service instructions and military publications) and conceptions of NATO through their certifying.

At present member states propose to the NATO 20 specialized Centres. Each of these Centres is focused on other specialized area. The ČR has after previous appreciation of all possibilities decided to commit for specializing the Army of the Czech Republic in Protection against weapons of mass destruction and has accepted the role of host country in building of an International Military Organisation in form of COE within its territory. This element is in the structures of NATO led as a Joint Chemical, Biological, Radiological and Nuclear Centre of Excellence (Joint CBRN Defence COE).

\section{Statistical Conception and Risk Processing}

At investment decision-making it is calculated an expected return of investment (ov) as a weighted probability average of potential profit abilities ( $p v)$ and a riskiness (risk rate) as a weighted probability average of deviations $p v$ from $o v$. Under standard deviation of profitability it is understood a spread $\sigma$ (dispersion) of standard $p v$ distribution and under a "sliminess of Gausian curve" variation coefficient.

On the basis of above mentioned it can be stated, that the riskiness means a significance $p v$ clustering round $o v$. This implies that, capital projects with bigger density of clustering are less risk, because they have smaller spread and slimmer Gaussian curve.

For calculations it determines, standard deviation equals percentage height of absolute risk. So it can be written down the relation: $\sigma=$ risk charge of investment $=r$.

Mean value of expected cash flows:

$$
\overline{P T}=\sum_{j=1}^{n} P T_{j} \cdot P_{j}
$$

where:

$P T_{j}$ : are individual cash flows of different variants;

$p_{j}$ : is a probability, that individual cash flow occurs;

$n$ : is number of expected cash flows variants.

There is accepted: $\sum p_{j}=1$ and $0 \leq p_{j} \leq 1$.

For full degree of risk expression in investment projects it is necessary to compare deviations of individual cash flows from average expected value, when higher deviations will signalize a riskier project.

Spread of expected cash flows from investment variants:

$$
\sigma^{2}=\sum_{j=1}^{\mathrm{n}}\left(P T_{j}-\overline{P T}\right)^{2} \cdot p_{j}
$$

Standard deviation:

$$
\sigma=\sqrt{\sigma^{2}}
$$

Bigger standard deviation of cash flows an appropriate project embodies, the bigger is its risk. For comparison of project riskiness with essentially different expected average values of cash flows we make use of variation coefficient $V$.

$$
V=\frac{\sigma}{P T}
$$


The higher a variation coefficient is, the higher an investment risk also is.

\section{Numerically Expressed Risk}

Risk can be expressed in numbers, so in quantitative way and in term of financial decision-making further numerically processed by calculus of probability. Probability, that expressed cash flow occurs in future, can be in percentage quantified as a possibility of its realization.

Probability of financial flow coming on can be found out:

(1) Objectively, it means by statistical analysis of historical data (condition is to have accessible statistically significant data);

(2) Subjectively, it means by estimation on a basis of risk factors effect consideration and with expert experience application.

\section{Methods of Useful Cost Analyse}

For international environment of NATO, there are suitable support methods - useful cost analysis (cost-output methods), namely, from following reasons:

(1) They make possible to measure inputs (costs on the actions under consideration of public policy) in relation to expected outputs (results of public policy);

(2) Application of these methods is relatively easy and provides at the same time relatively enough needful information for final decision;

(3) Mentioned methods are based on criteria application of economy, efficiency, and usefulness, so on criteria, that every manager of public sector is obliged to trace, who uses public funds.

To the cost-output methods belong these four basic cost-output methods:

(1) Cost minimization analyze (CMA): for appreciation these intends and projects, when variants under consideration have qualitatively and quantitatively analogical and comparable outputs; frequent using at public tender, where is only one appraising criterion - the price; criterion of selection is the lowest price;

(2) Cost and benefits analyze (CBA): for appreciation investment actions, when is possible and suitable to express results of public policy in the money; criterion of selection is the best ratio of benefits and costs;

(3) Cost efficiency analyze (CEA): for results appreciation of public funds, there are in units in kind form; criterion of selection is the lowest cost on unit in kind of output;

(4) Cost utility analyze (CUA): for results appreciation of public funds, when we measure a fulfilment grade of aim and a satisfaction grade with regard to spent costs.

Methods of cost utility analyze are suitable instruments for the best variant selection. Each of mentioned methods highlights a specific criterion (Veber, 2001). It is possible to consider the choice of appropriate method with regard to appraising criterion.

For cost output methods is characteristic that all mentioned methods measure inputs (costs) in monetary units. That means, if we want to use some of mentioned method for variant appreciation, it has to be known the cost quantification for the actions given by policy. It is a real prerequisite, because it can find the needed data in costing to given action, in budget, or in accounting.

\section{Evaluation of Public Projects Within the North Atlantic Treaty Organization}

Within evaluation of public projects in North Atlantic Treaty Organization (Alliance, NATO) it is possible to apply standard identical indicators of effectiveness as within capital planning in a commercial sphere. Their 
application in a public sector is, however, conditional by elaboration of both costs and benefits analyses (CBA - Cost-Benefit Analyze). In spite the fact a majority of Cost-Benefit Analyzes are accommodated with a narrow group of indicators, potentially employed are following:

$N P V$ : Net Present Value;

$N P V / I$ : Net Present Value/Investment;

$C$ / B: Benefit-Cost Ratio;

$P B$ : Pay-Back;

IRR: Internal Rate of Return.

Indicators, nevertheless, can have a double character in accordance with the fact if they consider a time factor in their calculation.

Static indicators: they do not respect the time factor and they are able to be used only in a case if the time factor does not have a substantial influence, for example, within projects with a short-termed lifetime. From above mentioned the possible statistic indicator is only an option of $P B$, it means a simple time of the economic return.

Dynamic indicators: they respect the time factor and they are employed wherever where it is calculated with longer time of project lifetime.

Within evaluation of public projects in a framework of private sector so called a private (financial) discount rate is employed. This one is understood as a market interest rate. However, it can be considered as average outgoings of a company capital.

Within evaluation of public projects within them, corporate outgoings and benefits are included in financial flow, the private rate is replaced by so called community, respectively social rate. Designation of social discount rate it very complicated. A lot of methods are currently used, nonetheless until this time was not found any consensus not even in European Union in this area. The problem is connected mainly with the effort to find the optimal height of social outgoings of opportunities. However, it is not still clear whether one value should have been valid generally for the whole national economy or if it should have been different for its single sectors.

\section{CBA Application Within the Joint CBRN Defence COE Activities}

In a practice life of the international military organization named as Joint Chemical, Biological, Radiological and Nuclear Defence Centre of Excellence (JCBRN Defence COE), a lot of situations have happened when it was necessary to consider either one or the whole group of projects in a condition of different presumptions. During decision-making processes have been used following indicators of effectiveness (Fischer, 2009).

\section{Clean Current Value-Net Present Value}

Net Present Value (NPV) belongs to dynamic indicators and it is defined as the difference of discount financial incomes, discount financial outgoings generated by the project during its lifetime, respectively as the difference between discount cash flow of single years and initial outgoings (Racmachadran \& Tsokos, 2009).

Net present value introduces the clean discount gain within observed period of time. Regarding the fact that its size is limited not only by absolute (nominal) values of cash flows but also by reliable chosen discount rate during discounting the counted value gives information to an investor about how the realized project is a 
better alternative for its capital or it offers its current placing or another project options.

$N P V$ can be expressed by the formula:

$$
N P V=\sum_{t=0}^{n} \frac{C F_{t}}{(1+r)^{t}}
$$

where:

$C F_{t}:$ is a nominal cash flow;

$t$ : reaches values from 0 to $n$;

$n$ : is the project lifetime;

$r$ : is the discount rate.

Calculation of $N P V$ is done for the whole set time of lifetime of the project. Calculated value can be interpreted based on comparison with the zero border. The fact that $N P V$ of designated project is bigger than zero does not mean that this project fulfills a criterion of effectiveness. It always depends on a particular situation of how many projects are evaluated, if they are somehow connected and if realization of one affects another one form the group. This is the reason why it is necessary to assess NPV's results in accordance with introduced circumstances.

\section{Index of Profitability—Net Present Value / Investment}

$N P V$ is very often completed by the index of profitability. It introduces a relative indicator which expresses the proportion of expected discount financial benefits from an investment to initial investment expense. While the clean current value introduces absolutely expressed difference between discount financial income from the investment and investment expenses, Net Present Value / Investment (NPV/I) expressed the proportion of discounted financial incomes investment expenses. Employment of the index is recommended at the time if it is chosen between a few concepts and capital resources are restricted. It means that it is not possible to accept all projects even if they have positive clean current value (Franc, 2006).

Calculation of the index of profitability NPV / I:

$$
N P V / I=\frac{\left(P V+C F_{0}\right)}{\left(-C F_{0}\right)}=\frac{\left[C F_{0}+\sum_{t=1}^{n} \frac{C F_{t}}{(1+r)^{t}}\right]}{\left(-C F_{0}\right)}
$$

respectively:

$$
N P V / I=\frac{\left[\sum_{t=0}^{n} \frac{C F_{t}}{(1+r)^{t}}\right]}{\left(-C F_{0}\right)}
$$

where:

$C F_{0}$ : is the cash flow in the year of 0 it means investment outgoings;

$r$ : is the discount rate;

$n:$ is the project lifetime;

$P V$ : is a current value.

\section{Proportion of Benefits and Outgoings-Benefit Cost-Ratio}

Indicators which catch the proportion between project's outgoings and yields exists a big number. They differs each other mostly in a way of both construction and predicative ability. Their employment depends 
mostly on the type of the project and the character of its carrier (Krč, 2009). One of the most employed forms presented in Benefit Cost-Ratio $(B / C)$ is expressed by the formula:

$$
B / C=\frac{P V B}{P V C}=\sum_{t=0}^{n} \frac{\frac{B_{t}}{(1+R)^{t}}}{\frac{C_{t}}{(1+r)^{t}}}
$$

where:

$P V B$ : is a current value of incomes;

$P V C$ : is a current value of outgoings;

$B_{t}$ : are benefits in a period if time $t$;

$t$ : reaches values from 0 to $n$;

$C_{t}$ : are outgoings in the period if time $t$;

$r$ : is a discount rate.

The base presumption for positive evaluation of the project is a result either bigger or equals to 1 , higher value of indicator shows on better economic return of embedded investments.

The indicator of $B / C$ in this form expresses the portion of discounted yields discounted outgoings within the project lifetime. Outgoings and benefits incorporates beyond financial incomes and outgoings also social-economy incomes and outgoings. The construction of the indicator respects cash-flows created in all project phases. Its employment enables rough comparison of projects between each other and, in the case of limited budget, their selection.

$B$ / $C$ is able to order project variations in the same way as the index $N P V$ does. This fact proves even an application within situation when $B / C$ creates the same ladder of project quality as $N P V / I$. In a practice life is even used $B / C$ instead of $N P V / I$ which is not too usual.

\section{Repayment Time (PB-Pay-Back)}

Repayment time introduces a number of years within them the project creates positive cash flows in height if invested project outgoings (Brizgalová, 2005).

Project repayment time in case of constant cash-flows in time. In case of the project which will generate each year the same cash-flows during its lifetime it is possible to conduct the calculation in a simple way.

$$
P B=\frac{I}{C F_{t}}
$$

where:

$C F_{t}$ : is the constant cash-flow pro all $t$ from 1 to $n$;

I: are investment outgoings.

Time repayment in case of variable cash-flows in time. Regarding cash-flows does not mostly have a constant character in simple years, it is not possible such as value divided by investment outgoings, and it is necessary to approach to cumulative counting of annual $C F$ till to height of investment outgoings.

$P B=$ Number of year of negative cumulative net $C F+\frac{I-\text { value net } C F \text { in the first year, when net } C F>0}{\text { year } C F \text { in the first year, when net } C F>0}$ where $I$ is investment outgoing. 
In the area of private sector there is $P B$ often used as the indicator to judgment when the investor's initial income returns his initial deposit. Neither such the case is not a primary decisive criteria because it is connected with certain disadvantages.

The $P B$ task in a public sector is lower, it has rather supportive task in the process of public project evaluation. This criterion can be used for example when if it is chosen between realization of two reciprocally excluded processes, which will be reached the same value of $N P V$ and the same value even within next evaluated criteria (Fotr, Dědina, \& Hrůzová, 2000). In such case project whose economic return is shorter can be chosen. Nevertheless, two variations of $P F$ exist:

(1) Single time repayment (does not takes into account the time factor);

(2) Discount time repayment (takes into account the time factor).

Time repayment, differently from other described indicators, it does not always have to be only the dynamic indicator. In practice it is often counted from non-discounted cash-flows despite the fact that within project with long-term lifetime comes to distortion of predicated abilities (Hindls, Hronová, \& Novák, 1999).

\section{Internal Rate of Return-Internal Rate of Return}

Although the primary indicator for assessing the effectiveness of the project $N P V$, Internal Rate of Return (IRR) is a practice used indicator. Detailed knowledge of IRR indicator is very important. In most cases the result of IRR NPV reflects the NPV result; however, it does not have to by always the same. The problem is that can occur specific situations where the IRR is not easy to interpret. IRR can have multiple values, and the result may be in contrary to the indicator $N P V$, depending on the value of the discount rate used. For most of these pitfalls however, there are solutions (Ochrana, 2004).

The internal rate of return can be regarded as one of the main alternatives to the NPV indicators. These include the Dynamic Indicators of efficiency and, unlike the NPV IRR taken when comparing investment alternatives in the scale of the project (Smejkal \& Rais, 2003). The $I R R$ can be viewed as a rate (discount rate) at which the project $N P V$ is equaled zero. IRR can be derived from the relations:

$$
0=\sum_{t=0}^{n} \frac{C F_{t}}{(1+I R R)^{t}}
$$

where:

$C_{F}$ : is the nominal cash-flow;

$t$ : reaches values from 0 to $n$;

$n:$ in lifetime in years.

\section{Conclusions}

One of the major problems connected with the application of CBA in terms of the North Atlantic Alliance is the lack of quantification of the basic and most frequently-occurring costs and benefits. The same problem can be seen as the important parameters, especially the discount bond. This article is not to reward the most frequent target costs and benefits, nor to determine the correct value of financial and social discount rates. Rather, it provides the necessary impetus for a broader discussion of the incompleteness of the current methodological background, which no scope for creating high-quality studies and the public sector is deprived of an important method of evaluation of public projects. Cost-benefit analysis has considerable potential to become a NATO widely applied method for evaluation of public projects, not only those whose aim is to 
activate the potential of local resources. A prerequisite will be a lot more research to ensure the adaptation method transatlantic conditions.

\section{References}

Brizgalová, L. (2005). Economy, military expenses and safeness (pp. 34-39). University of Defence, Brno.

Fischer, J. (2009). Applications of mathematics and statistics in economy (pp. 312-317). High School of Economy, Economica, Praha.

Fotr, J., Dědina, J., \& Hrůzová, H. (2000). Managerial decision making (pp. 67-89). Ekopress, Praha.

Franc, P., Krátký, J., \& Vondráčková, P. (2006). Possibilities of CBA at evaluation of specific local sources activation in provincial space (pp. 56-73). Pardubice: First regional developing Inc..

Hindls, R., Hronová, S., \& Novák, I. (1999). Data analysis in managerial decision making (pp. 112-135). Praha: Grada Publishing.

Krč, M. (2009). Mathematical methods and their usage in environment of defence and effectiveness (pp. 78-99). University of Defence, Brno.

Ochrana, F. (2004). Public funds order's: Methods and philosophy of efficient evaluation and selection (pp. 47-53). Ekopress, Praha.

Racmachadran, K. M., \& Tsokos, Ch. P. (2009). Mathematical statistics with applications (pp. 423-501). USA: Elsevier Academic Press.

Smejkal, V., \& Rais, K. (2003). Risk management (pp. 113-125). Praha: Grada Publishing.

Veber, J. (2001). Management: Bases-prosperity-globalization (pp. 236-254). Praha: Management Press. 